\title{
Midkine is involved in tubulointerstitial inflammation associated with diabetic nephropathy
}

\author{
Tomoki Kosugi ${ }^{1,2}$, Yukio Yuzawa², Waichi Sato ${ }^{2}$, Hanayo Arata-Kawai ${ }^{2}$, Norihiko Suzuki ${ }^{3}$, Noritoshi Kato ${ }^{1,2}$, \\ Seiichi Matsuo ${ }^{2}$ and Kenji Kadomatsu ${ }^{1}$
}

The concept that inflammation plays a crucial role in the pathogenesis of diabetic nephropathy has been recently emerging, although the principal pathology of diabetic nephropathy comprises glomerular sclerosis and associated changes in nephrons. Here, we identified the growth factor midkine (MK) as a novel key molecule involved in inflammation associated with Streptozotocin-induced diabetic nephropathy. The tubulointerstitial damage, as assessed as morphological changes, osteopontin expression, collagen I deposition and macrophage infiltration, were strikingly less in MK-deficient $\left(\mathrm{Mdk}^{-/-}\right)$mice than in $M \mathrm{dk}^{+/+}$mice. Monocyte chemoattractant protein (MCP)-1 expression, but not that of intercellular adhesion molecule-1, was also lower in $\mathrm{Mdk}^{-1-}$ mice. High glucose upregulated MK expression in primarycultured tubular epithelial cells, and induced MCP-1 to a larger extent in Mdk ${ }^{+/+}$cells than in $M d k^{-/-}$cells. Correspondingly, the combination of exogenous MK and high glucose enhanced MCP-1 expression in $\mathrm{Mdk}^{-/-}$cells. Furthermore, high glucose and oxidant stress enhanced MK expression in macrophages. Consistent with the findings in the mouse model, MK expression was detected in the glomeruli, tubular epithelium and interstitium of kidneys from patients with diabetic nephropathy. Our data indicate that MK plays a critical role in the tubulointerstitial inflammation associated with diabetic nephropathy through activation of the MCP-1 pathway.

Laboratory Investigation (2007) 87, 903-913; doi:10.1038/labinvest.3700599; published online 2 July 2007

KEYWORDS: midkine; diabetic nephropathy; tubulointerstitial damage; MCP-1

Diabetic nephropathy is a life-threatening condition associated with diabetes mellitus and is the leading cause of endstage renal failure for patients in many countries. ${ }^{1,2}$ Diabetic nephropathy is characterized by sequential functional progression from hyperfiltration to microalbuminuria to macroalbuminuria to renal failure. This progression is accompanied by morphological changes, including glomerular basement membrane thickening, mesangial expansion, arterial hyalinosis, glomerular sclerosis and tubulointerstitial fibrosis. Although diabetic nephropathy was not considered an inflammatory disease in the past, there is an increasing body of evidence that inflammation is involved in the pathogenesis of this disease. ${ }^{3-7}$ However so far, only a few molecules have been identified as key players in this inflammation, that is, monocyte chemoattractant protein (MCP)-1, intercellular adhesion molecule (ICAM)-1, nuclear factor- $\kappa \mathrm{B}(\mathrm{NF}-\kappa \mathrm{B})$ and tumor necrosis factor- $\alpha^{3-9}$

We recently demonstrated that the growth factor midkine (MK) plays a critical role in the pathogenesis of diabetic nephropathy, using a mouse diabetes model induced by Streptozotocin (STZ). ${ }^{10}$ STZ impairs $\beta$-cells in the pancreas, thereby inducing hyperglycemia, and thus has been used to induce type I diabetes mellitus in model systems. We found strikingly milder diabetic nephropathy in MK-deficient $\left(\mathrm{Mdk}^{-1-}\right)$ mice than in $\mathrm{Mdk} \mathrm{k}^{+/+}$ones. ${ }^{10}$ Consistent with this finding, MK expression was induced in the glomerular mesangium of $M d k^{+/+}$mice with diabetic nephropathy and in primary-cultured mesangial cells exposed to high glucose. ${ }^{10}$ MK accelerated signaling evoked by high glucose in primarycultured mesangial cells, that is, production of transforming growth factor (TGF)- $\beta_{1}$, and phosphorylation of protein kinase $\mathrm{C}$ and extracellular signal-regulated kinase. ${ }^{10}$

MK is a heparin-binding growth factor, and has been implicated in neuronal survival and differentiation, cancer development and inflammation-related diseases. ${ }^{11} \mathrm{MK}$ is frequently intensely expressed in human carcinoma tissues, and a high MK level is associated with a poor prognosis. ${ }^{12}$ MK antisense oligonucleotides (ODNs) suppress tumor

\footnotetext{
'Department of Biochemistry, Nagoya University Graduate School of Medicine, Nagoya, Aichi, Japan; ${ }^{2}$ Department of Nephrology of Internal Medicine, Nagoya University Graduate School of Medicine, Nagoya, Aichi, Japan and ${ }^{3}$ Kojyukai Tawada Medical Clinic, Nagoya, Aichi, Japan

Correspondence: Dr K Kadomatsu, MD, PhD, Department of Biochemistry, Nagoya University Graduate School of Medicine, 65 Tsurumai-cho, Showa-ku, Nagoya, Aichi 466-8550, Japan. E-mail: kkadoma@med.nagoya-u.ac.jp
} 
growth in nude mice. ${ }^{13}$ With regards to the relation between MK and inflammation-related diseases, there is a growing body of evidence, as follows. First, the blood MK level is elevated in human rheumatoid arthritis. ${ }^{14}$ Second, $M d k^{-/-}$ mice exhibit significantly milder phenotypes than $M d k^{+/+}$ mice in models of arterial restenosis, ischemic reperfusioninduced renal damage, cisplatin-induced nephropathy and rheumatoid arthritis. ${ }^{14-17}$ Finally, an MK antisense ODN ameliorates arterial restenosis, ischemic reperfusion-induced renal damage and cisplatin-induced nephropathy. ${ }^{17-19}$ In addition to these indirect data on the relationship between MK and inflammation-related diseases, MK directly induces macrophage migration. ${ }^{15}$

We hypothesized that MK plays roles not only in mesangial pathological changes, but also in the inflammation associated with diabetic nephropathy. This study was carried out to address this hypothesis. We report here the critical role of MK in the pathogenesis of interstitial renal damage associated with diabetic nephropathy.

\section{MATERIALS AND METHODS \\ Human Kidney Tissues}

The indication of renal biopsy was provided according to the criteria of the Japanese Society of Nephrology. All patients who needed histological examination for diagnosis were subjected to renal biopsy. Three hundred and ninety-eight cases were examined at Nagoya University for the past 15 months. Eight cases were non-insulin-dependent diabetic nephropathy, for which it was necessary to exclude other diseases by renal biopsy. We used 19 cases of minor glomerular abnormality as controls. Kidney tissues from eight cases showed characteristic pathological features of diabetic nephropathy, that is, glomerular sclerosis, interstitial fibrosis, tubular basement membrane thickening and tubular atrophy, as judged on electron microscopic analysis, periodic acidSchiff (PAS) staining, Masson-trichrome staining and complement staining. The specimens with minor glomerular abnormality exhibited only minute pathological changes. Tissue samples for immunohistochemical detection of MK were fixed in $4 \%$ paraformaldehyde, embedded in paraffin and then cut into $4-\mu \mathrm{m}$ sections. MK staining was performed as described previously. ${ }^{10}$ The first antibody used was chicken anti-human MK (IgY). Negative controls were performed by the replacement of primary antibodies with species-matched antibodies. Approval for the use of kidney tissues was obtained from the Institutional Ethics Committee of Nagoya University School of Medicine. Informed consent was provided according to the Declaration of Helsinki.

\section{Animals and Experimental Design}

$M d k^{-1-}$ mice were generated as described previously. ${ }^{10}$ After backcrossing of $M d k^{+/-}$mice for 14 generations with 129/SV mice, $M d k^{+/-}$mice were mated with each other to generate $M d k^{+1+}$ and $M d k^{-1-}$ mice, which were used in this study. Experiments were performed on 8- to 12-week-old female
$M d k^{+/+}$or $M d k^{-/-}$mice weighing 20-25g. The mice were housed under controlled environmental conditions, and maintained with standard food and water.

Diabetes mellitus was induced in mice by means of single intraperitoneal injections of STZ $(140 \mathrm{mg} / \mathrm{kg}$ body weight; Sigma, St Louis, MO, USA) on two consecutive days, as described previously. ${ }^{10}$ The same archive tissue as the previous paper ${ }^{10}$ has been used in this study. The blood glucose levels were measured weekly after injection of STZ using a glucometer, and mice with blood glucose levels of more than $250 \mathrm{mg} / \mathrm{dl}$ were regarded as being in a diabetic state. STZinjected mice were also compared with non-diabetic mice of matched ages. Mice were killed at 2, 4 and 6 months after injection of STZ. Kidneys were removed for examination. Kidney tissues were processed for histology, and protein and mRNA extraction. All of the animal experiments were performed in accordance with the animal experimentation guidelines of Nagoya University School of Medicine.

\section{Morphological Assessment}

The removed kidneys were fixed in $4 \%$ paraformaldehyde, embedded in paraffin and then cut into $4-\mu \mathrm{m}$ sections. They were examined on PAS or Masson-trichrome staining. The sections were analyzed to evaluate tubulointerstitial damage in each region by light microscopy (magnification $\times 200$ ). The percentage of atrophic tubules (tubular dilation, detachment of tubular epithelial cells (TECs) and condensation of tubular nuclei) was assessed by scoring 400 renal cortical tubules in randomly selected fields for each subject. ${ }^{5-7}$ Eight subjects were examined for each experimental group. For the morphometric analysis, the extent of interstitial fibrosis was determined by assessing the Masson-trichrome-positive areas within the renal cortex excluding glomerulus. Their areas were measured using MetaMorph 6.3 image analysis computer program (Universal Imaging Co., West Chester, PA, USA). All scoring was performed on blinded slides by two observers.

\section{Immunofluorescence Staining for Type I Collagen and Macrophages}

Parts of the kidney tissues were snap-frozen in liquid nitrogen. Sections (4- $\mu \mathrm{m}$ thick) were cut with a cryostat, and then fixed in acetone. The cryosections were stained with polyclonal rabbit anti-rat type I collagen (Chemicon International, Temecula, CA, USA) or monoclonal rat anti-mouse monocyte-macrophage marker F4/80 (Serotec, Oxford, UK), followed by detection with fluorescein isothiocyanate (FITC) goat anti-rabbit IgG (Zymed Laboratories, San Francisco, CA, USA) or FITC rabbit anti-rat IgG (Zymed Laboratories). Type I collagen-stained areas were measured using MetaMorph 6.3 image analysis computer program as described previously $(n=8) .{ }^{10}$ Macrophages positive for F4/80 were counted by examining 10 fields of the cortex under a microscope at $\times 200$ magnification in a blind manner. 


\section{Immunohistochemical Detection of Osteopontin and Intercellular Adhesion Molecule-1}

The sections embedded in paraffin were stained with polyclonal rabbit anti-mouse osteopontin (LSL Co., Tokyo, Japan) or mouse monoclonal ICAM-1 antibody (R\&D Systems, Minneapolis, MN, USA), followed by detection with biotin-conjugated goat anti-rabbit IgG (Nichirei, Tokyo, Japan) or biotin-conjugated goat anti-mouse IgG (ICN Pharmaceuticals Inc., Aurora, OH, USA). Immunostaining was performed by the streptavidin-biotin (Streptavidin was from Chemicon International, Temecula, CA, USA) immunoperoxidase method. The staining was visualized with 3,3'-diaminobenzidine (Dako, Carpinteria, CA, USA), a brown color being produced. To assess tubulointerstitial injury, osteopontin-positive tubules were measured in cortical fields, using the MetaMorph 6.3 image analysis computer program (Universal Imaging Co., West Chester, PA, USA). Negative controls involved replacement of the primary antibodies with species-matched antibodies.

\section{Northern Blotting}

Mouse kidney tissues were snap-frozen in liquid nitrogen for total mRNA isolation, as described previously. ${ }^{16}$ To standardize the Northern blots, we used a housekeeping gene, glyceraldehyde-3-phosphate dehydrogenase (GAPDH), as an internal control. Chemokine expression, including that of MCP-1 fibronectin, IL- $1 \beta$ and TGF- $\beta_{1}$, was assessed.

\section{Western Blot Analysis}

Mouse kidney tissues were snap-frozen in liquid nitrogen for protein isolation. Western blot analysis was performed as described previously. ${ }^{10}$ The blots were subsequently incubated with rabbit anti-MK antibody, mouse monoclonal anti-ICAM-1 antibody or monoclonal anti- $\beta$-actin antibody (Sigma-Aldrich, St Louis, MO, USA), followed by incubation with peroxidase-conjugated rabbit IgG or mouse IgG (Jackson Immunoresearch Laboratories Inc., West Grove, PA, USA). Proteins were visualized with an enhanced chemiluminescence detection system (Amersham Pharmacia, Amersham Biosciences, Piscataway, NJ, USA). The density of each band was measured using the public domain $\mathrm{NIH}$ Image program.

\section{Cell Culture}

TECs were isolated from the kidneys of adult $\mathrm{Mdk}^{+/+}$or $M d k^{-/-}$mice, and then cultured in K1 medium $(224.25 \mathrm{ml}$ Ham's F12, $226.25 \mathrm{ml}$ Dulbecco's modified Eagle's medium (DMEM) and $12.5 \mathrm{ml}$ HEPES) containing 10\% fetal bovine serum (GIBCO BRL, Gaithersburg, MD, USA) and hormones, as described previously. ${ }^{16}$ They were used between the fourth and eighth passages. They were determined to be of proximal tubular origin by means of immunofluorescence histochemistry: cells were stained positively for cytokeratin (ENZO Diagnostics, Inc., Farmingdale, NY, USA), vimentin (ICN Biomedicals Inc., Aurora, OH, USA), and alkaline phosphatase, but negatively for CD31 (BD Biosciences Pharmingen, San Diego, CA, USA) and $\alpha$-smooth muscle actin.

Subconfluent TECs were incubated in serum-free medium for $24 \mathrm{~h}$ to arrest and synchronize cell growth. After this period, the cells were treated with different concentrations of D-glucose or D-mannitol $(0,10,20$ or $40 \mathrm{mM})$ for $24 \mathrm{~h}$ in the dose-dependent study. The medium was changed to fresh serum-free DMEM containing $20 \mathrm{mM}$ D-glucose (Sigma Chemical Co., St Louis, MO, USA) or DMEM containing 20 mM D-mannitol (Sigma Chemical Co.) for 0, 3, 6, 12, 24 or $48 \mathrm{~h}$ in the time-course study. D-Mannitol was used as a negative control for 'high glucose' loading. Cells were then lysed in RIPA buffer ( $50 \mathrm{mM}$ Tris- $\mathrm{HCl}, 150 \mathrm{mM} \mathrm{NaCl}, 1 \%$ Nonidet P, $1 \%$ deoxycolic acid and $0.05 \%$ sodium dodecyl sulfate (SDS)) containing $0.25 \mathrm{mM}$ phenylmethylsulphonyl fluoride, kept on ice for $60 \mathrm{~min}$, and then centrifuged at $15000 \mathrm{~g}$ for $10 \mathrm{~min}$ at $4^{\circ} \mathrm{C}$. The supernatants were then subjected to SDS-polyacrylamide gel electrophoresis (PAGE) and Western blotting.

\section{Preparation and Stimulation of Mouse Peritoneal-Elicited Macrophages}

Mouse peritoneal macrophages were elicited by injection of $2 \mathrm{ml}$ of $3 \%$ thioglycollate medium (Wako, Osaka, Japan) intraperitoneally, and were collected by peritoneal lavage with $5 \mathrm{ml}$ of ice-cold phosphate-buffered saline (PBS) supplemented with EDTA-2Na 4 days after intraperitoneal injection. Cells were pooled from six mice and centrifuged at $500 \times g$ for $5 \mathrm{~min}$ at room temperature. They were then suspended at $1 \times 10^{6}$ cells/ml in RPMI 1640 (Sigma Chemical Co.) containing 3\% fetal bovine serum, and $2 \mathrm{ml}$ aliquots of the suspension were plated on 12-well tissue culture plates at $37^{\circ} \mathrm{C}$ in a $5 \% \mathrm{CO}_{2}$ incubator. After 90 min incubation, the cells were thoroughly washed with PBS to remove nonadherent ones. The cells were then incubated in RPMI 1640 containing $0.2 \%$ fetal bovine serum for $2 \mathrm{~h}$ to arrest and synchronize cell growth. ${ }^{20}$ After this time, the cells were treated with different concentrations of D-glucose (5.4, 20 or $40 \mathrm{mM}$ ) for $30 \mathrm{~h}$. Moreover, they were incubated with 0.5 or $1 \mathrm{mM}$ hydrogen peroxide for 60 or $120 \mathrm{~min}$, respectively. The supernatants and cell lysates were then subjected to SDS-PAGE and Western blotting.

\section{Monocyte Chemoattractant Protein-1 Protein Enzyme-Linked Immunosorbent Assay}

After cell growth had been synchronized, subconfluent TECs were incubated in fresh DMEM containing $20 \mathrm{mM}$ D-glucose. Cell culture supernatants were collected after a certain time and the MCP-1 levels were measured with an enzyme-linked immunosorbent assay (ELISA) kit (R\&D Systems, Minneapolis, MN, USA) according to the manufacturer's instructions. In another experiment, cells were exposed to $20 \mathrm{mM}$ D-glucose medium in the presence of $100 \mathrm{ng} / \mathrm{ml}$ human 
recombinant MK for 24 or $48 \mathrm{~h}$. The results were normalized as to the total protein concentration.

\section{Statistical Analysis}

All values are expressed as means \pm s.e. Statistical analysis was performed with unpaired, two-tailed Student $t$-tests for single comparisons or ANOVA for multiple comparisons. A $P$-value of $<0.05$ was taken to indicate a significant difference.

\section{RESULTS \\ Midkine Induction was Found in Human Diabetic Nephropathy}

Human kidney tissue samples were obtained by needle biopsy for differential diagnosis, and eight cases were diagnosed as having diabetic nephropathy, as described in Materials and methods. Nineteen cases of minor glomerular abnormality were used as control in this study. Clinical characteristics of these cases are summarized in Table 1. Strong tubular atrophy, interstitial fibrosis and interstitial cell infiltration were evident in the specimens of diabetic nephropathy, in which MK induction was detected in the glomeruli, tubules and interstitium (Figure 1a-c). MK expression was detected in all eight cases examined, which exhibited different states of diabetic nephropathy (data not shown). In contrast, MK expression was observed to be faint, if at all, in the interstitium of minor glomerular abnormality (Figure 1d). These features were consistent with the MK expression pattern in a mouse model induced by $S T Z^{10}$ and prompted us to examine the biological significance of $\mathrm{MK}$ in tubulointerstitial damage associated with diabetic nephropathy.

\section{Tubulointerstitial Damage is Less Marked in MK-Deficient Mice}

STZ injection into mice did not cause any apparent body weight loss without insulin treatment during the experimental period. There were no significant differences in the blood glucose level between $M d k^{+/+}$and $M d k^{-1-}$ mice. ${ }^{10}$

We compared the degrees of tubulointerstitial damage in $M d k^{+1+}$ and $M d k^{-/-}$mice. Tubular dilation was observed in $M d k^{+1+}$ mice as early as a month after STZ injection on light microscopy (data not shown). At 2 months after STZ injection, $M d k^{+1+}$ mice exhibited more tubular dilation as compared with $M d k^{-/-}$mice (Figure 2A-b and f), which had become more diffuse and severe at 4 and 6 months
(Figure 2A-c and d). At 4 months, the tubulointerstitium of $M d k^{+1+}$ mice also showed tubular atrophy, as demonstrated by tubular dilation, detachment of TECs and condensation of tubular nuclei (Figure 2B). By contrast, $M d k^{-/-}$mice showed only a little tubular atrophy at 4 and 6 months (Figure $2 \mathrm{~A}-\mathrm{g}$ and $\mathrm{h}$ ). Tubulointerstitial injury was found in both proximal and distal tubules in $M d k^{+1+}$ mice, whereas it was almost only found in distal ones in $M d k^{-1-}$ mice. Interstitial fibrosis, as assessed by Masson-trichrome staining, was evident at 2 months in $M d k^{+/+}$mice (data not shown), and more diffuse at 6 months (Figure 2C). At 6 months, $M d k^{+1+}$ mice exhibited more interstitial fibrosis as compared with $M d k^{-/-}$ mice (Figure 2C). Non-diabetic $M d k^{+/+}$and $M d k^{-/-}$ mice at 4 months did not show pathological changes at all (Figure 2D). The results at 2 and 6 months were the same as that at 4 months (data not shown).

The quantitative analyses regarding the number of atrophic tubules and the degree of interstitial fibrosis shown in Figure 2A and $\mathrm{C}$ was performed under light microscopy by the methods described in Materials and methods. The number of atrophic tubules in $M d k^{+/+}$mice increased with time, whereas that in $\mathrm{Mdk}^{-/-}$mice was consistently less (Figure 2E). There was significantly more interstitial fibrosis in $M d k^{+/+}$than $\mathrm{Mdk}^{-/-}$mice after 4 months (Figure 2E). Consistent with these findings, renal function evaluated as to urine-albumin/urine-creatinine, urine-protein/urine-creatinine and blood urea nitrogen was significantly worse in $M d k^{+/+}$mice than $M d k^{-1-}$ mice in this diabetes model. ${ }^{10}$

Deposition of type I collagen is a hallmark of interstitial fibrosis. Type I collagen-stained areas had increased in $M d k^{+/+}(14.8 \pm 3.2 \%)$ and $M d k^{-/-}$mice $(6.3 \pm 3.8 \%)$ at 4 months, and to a higher extent in $M d k^{+/+}$mice $(P<0.05$, $n=6$ ) (Figure 3A). Osteopontin staining was performed for assessment of tubulointerstitial damage. ${ }^{21}$ At 6 months, osteopontin-positive tubules were observed more in $\mathrm{Mdk}^{+/+}$than $M d k^{-/-}$mice (Figure 3B). Immunohistochemical staining for osteopontin at 2, 4 and 6 months was further evaluated quantitatively with the aid of an image analysis program. There were significantly more osteopontin-positive areas in $M d k^{+/+}$mice than $M d k^{-/-}$mice (Figure 3C). Taken together, these data clearly indicate that tubular damage accompanying interstitial fibrosis is induced in the model employed in this study, and is more marked in $M d k^{+/+}$mice than in $\mathrm{Mdk}^{-1-}$ mice.

Table 1 Clinical characteristics of renal biopsy

\begin{tabular}{lrcccccccc}
\hline & $N$ & Age & BMl & BUN (mg/dl) & s-Cre $(\mathrm{mg} / \mathrm{dl})$ & Ccr (ml/min) & HbA1c (\%) & s-Alb (g/dl) & UP (g/day) \\
\hline Diabetic nephropathy & 8 & $53.9 \pm 15.0$ & $27.8 \pm 9.67$ & $21.7 \pm 6.34$ & $1.26 \pm 0.49^{*}$ & $71.0 \pm 62.4$ & $7.1 \pm 1.1^{*}$ & $2.7 \pm 0.9$ & $7.1 \pm 4.6^{*}$ \\
Minor glomerular abnormality & 19 & $43.9 \pm 14.4$ & $27.31 \pm 10.3$ & $16.5 \pm 8.01$ & $0.80 \pm 0.24$ & $87.5 \pm 30.5$ & $5.2 \pm 0.3$ & $2.43 \pm 1.2$ & $3.3 \pm 2.2$
\end{tabular}

BMI, body mass index; BUN, blood urea nitrogen; Ccr, creatinine clearance; s-Alb, serum albumin; s-Cre, serum creatinine; HbA1c, hemoglobin A1c; UP, urinary protein.

${ }^{*} P<0.01$ versus minor glomerular abnormality. 

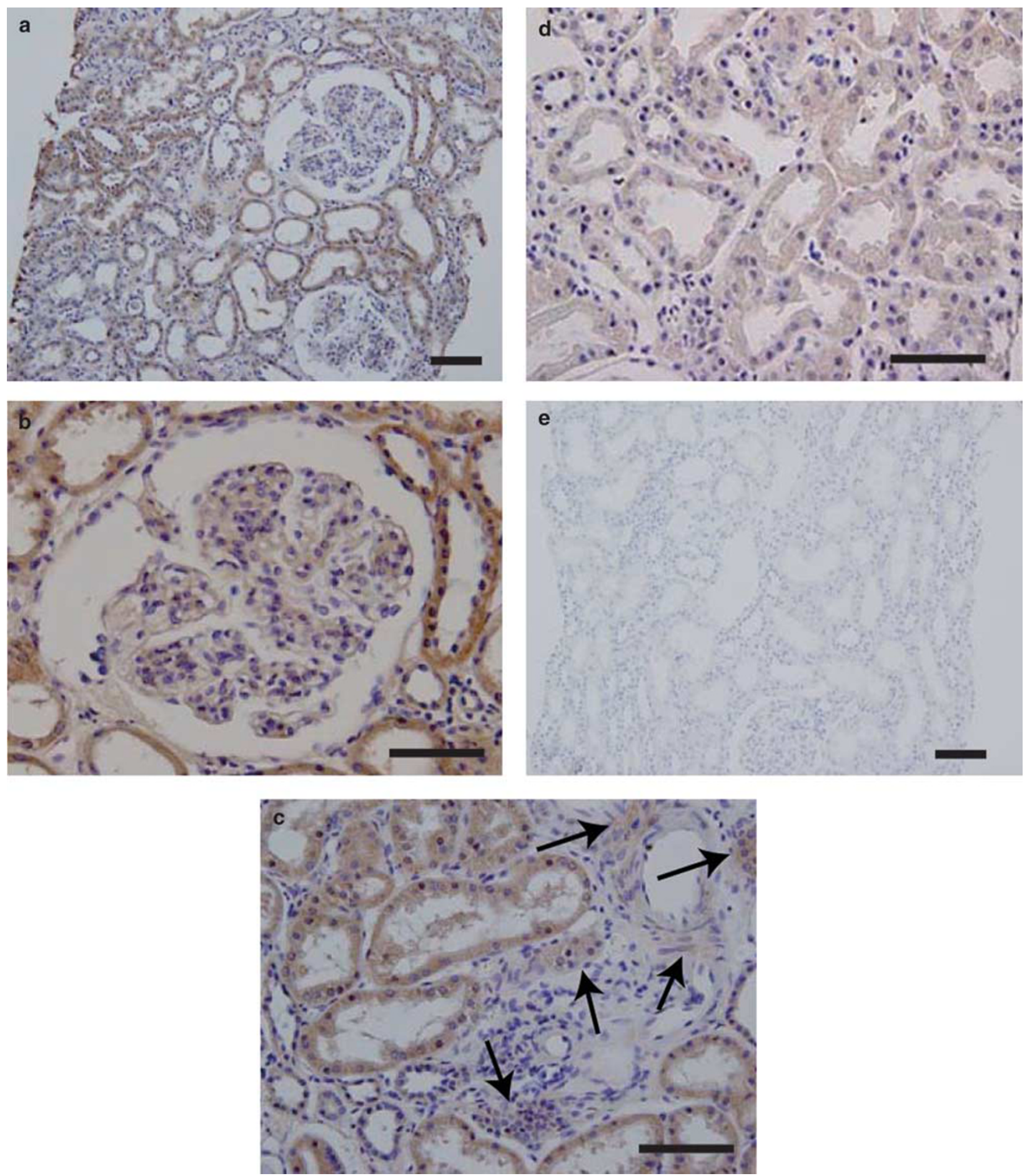

Figure 1 Human MK expression. Immunohistochemical staining of human renal biopsies with MK antibody. (a-c) Diabetic nephropathy. Arrow, positive staining of interstitial area. (d) Minor glomerular abnormality. (e) Negative control with species-matched (chicken IgY) antibody. Bar, $100 \mu \mathrm{m}$.

\section{Macrophage Infiltration and Induction of MCP-1 are Suppressed in $\mathrm{Mdk}^{-1-}$ Mice}

Pathologic morphological changes of tubules were associated with macrophage infiltration. We found that the number of infiltrating macrophages into the interstitium had increased in $M d k^{+/+}$mice a month after STZ injection (data not shown), and it was markedly lower in $M d k^{-/-}$than $M d k^{+/+}$ mice at 2 and 4 months (Figure 3D).

As MCP- 1 is the major chemoattractant for macrophages, we next investigated MCP-1 expression. MCP- 1 mRNA increased significantly in $M d k^{+/+}$mice, whereas the increase was markedly less in $M d k^{-1-}$ mice during the experimental 

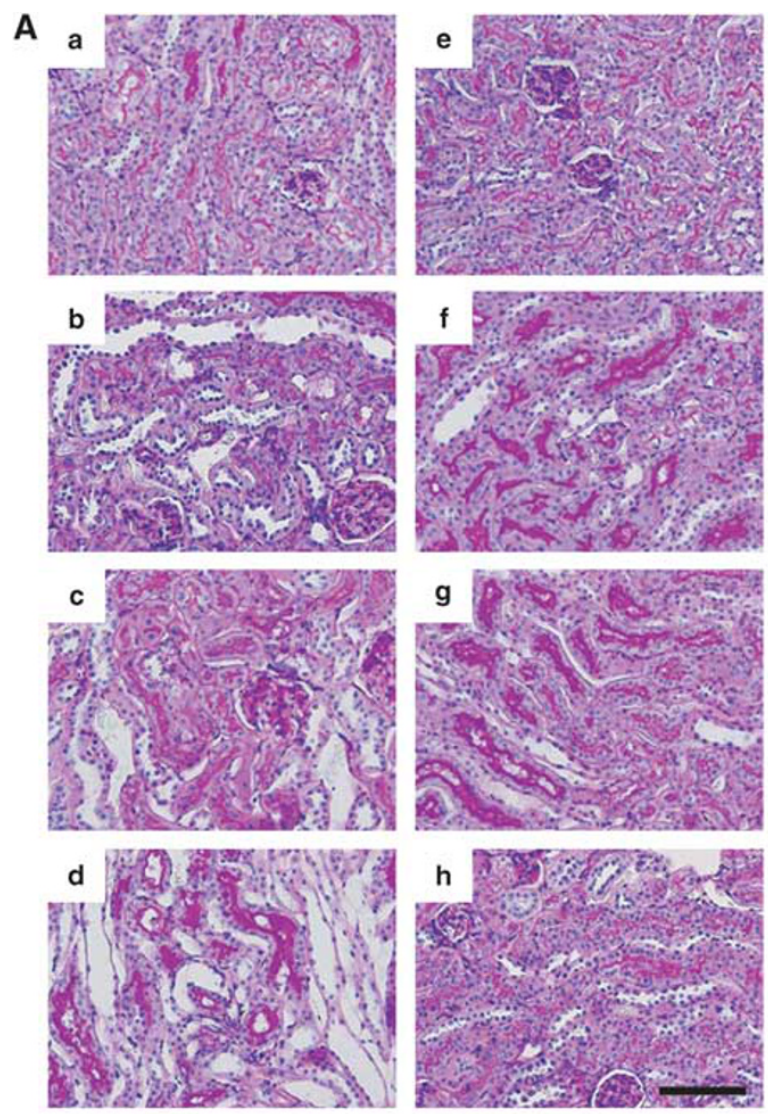

B
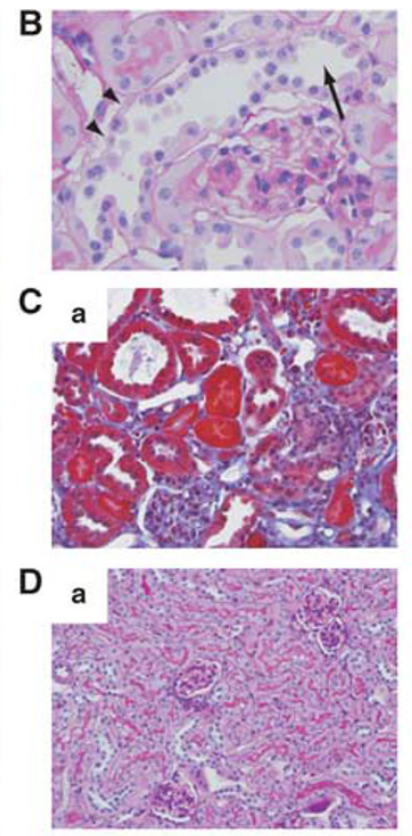

E
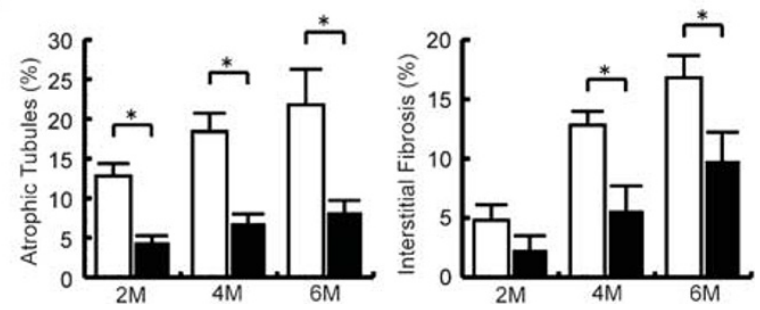

Figure 2 Tubulointerstitial histology of STZ-induced nephropathy in $M d k^{+/+}$and $M d k^{-1-}$ mice. (A) The tubulointerstitium at 0, 2, 4 and 6 months, respectively, was visualized by PAS staining. (a-d) $M d k^{+/+}$mice; (e-h) $M d k^{-/-}$mice. (a and e) Pre-injection; (b and f) 2 months; (c and g) 4 months; (d and h) 6 months. Bar, $100 \mu \mathrm{m}$. (B) The tubular damage in $M d k^{+/+}$mice at 4 months on PAS staining. Two representative areas are shown. Arrow, tubular dilation; arrowhead, tubular degeneration. Bar, $50 \mu \mathrm{m}$. (C) The tubulointerstitium at 6 months was visualized by Masson-trichrome staining. (a) Mdk ${ }^{+/+}$mice; (b) $M d k^{-1-}$ mice. Bar, $50 \mu \mathrm{m}$. (D) The tubulointerstitium of non-diabetic mice at 4 months was visualized by PAS staining. (a) $\mathrm{Mdk}^{+/+}$mice; (b) $\mathrm{Mdk}^{-/-}$mice. Bar, $100 \mu \mathrm{m}$. (E) Quantitative analyses of the tubulointerstitial damage in $M d k^{+/+}$and $M d k^{-/-}$mice. The number of atrophic tubules and the degree of interstitial fibrosis were scored as described in Materials and methods. Data are means (columns) and s.e. (bars). White columns, Mdk $+/+$ mice; black columns, Mdk-/- mice. ${ }^{*} P<0.05 . n=8$.

period (Figure $4 \mathrm{~A}$ and $\mathrm{B}$ ). In contrast to $\mathrm{MCP}-1$, there were no significant differences in the mRNA expression of TGF- $\beta_{1}$, fibronectin and IL-1 $\beta$ between $M d k^{+/+}$and $M d k^{-/-}$mice (Figure 4C). Macrophage inflammatory protein-2 mRNA did not show any differences either (data not shown).

ICAM-1 has been implicated in the firm adhesion step of inflammatory cell infiltration, and a deficiency of it causes suppression of diabetic nephropathy. ${ }^{4,5}$ However, ICAM-1 expression was enhanced during the course of diabetic nephropathy in similar manner in $\mathrm{Mdk}^{+/+}$and $\mathrm{Mdk^{-/- }}$ mice (Figure 4D-F). Apparently enhanced expression of ICAM-1 was found in the peri-tubular vasculature at 2 months and afterwards in the two genotypes (Figure 4D-F).

\section{Induction of MK and MCP-1 Protein Proximal Tubular Epithelial Cells in Culture}

We next determined the direct effect of glucose on MK expression in primary-cultured TECs. D-Glucose, 20 and
$40 \mathrm{mM}$ exposure for $24 \mathrm{~h}$, induced $\mathrm{MK}$ protein expression in primary-cultured TECs, whereas D-mannitol exposure did not, indicating that the MK induction was attributable to high glucose-mediated signaling, and not an osmotic pressure change (Figure 5a and $\mathrm{b}$ ). The temporal expression profiles indicated that both D-glucose and D-mannitol tended to induce $\mathrm{MK}$ expression in early phases, but that MK expression gradually decreased after $12 \mathrm{~h}$ exposure in the case of D-mannitol (Figure $5 \mathrm{c}$ and d). By contrast, D-glucose re-induced MK expression after $24 \mathrm{~h}$ exposure (the mechanism of this type of profile remains to be verified), and consequently there were significant differences in MK expression at 24 and $48 \mathrm{~h}$ between D-glucose and D-mannitol treatment (Figure $5 \mathrm{c}$ and d). The MK levels after 24 and $48 \mathrm{~h}$ exposure to high glucose were significantly higher than that at $0 \mathrm{~h}$ exposure (Figure 5d). Furthermore, a high concentration $(1 \mathrm{mM})$ of STZ did not have any effect on MK expression in primary-cultured TEC (data not shown), 
A
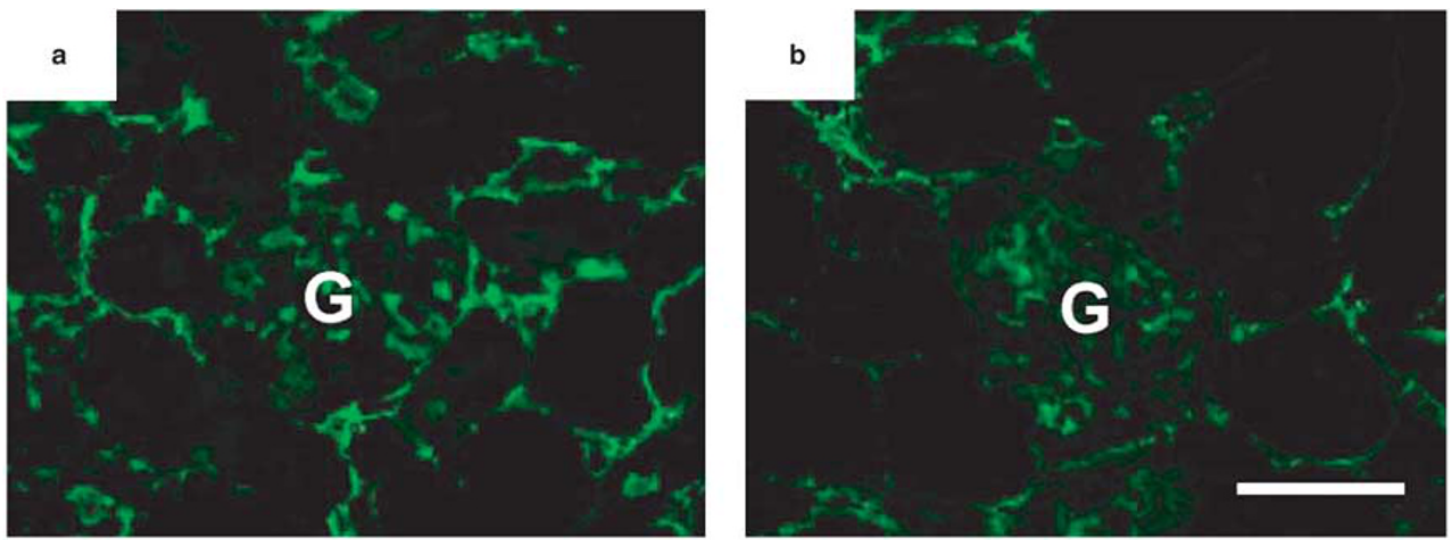

B


C
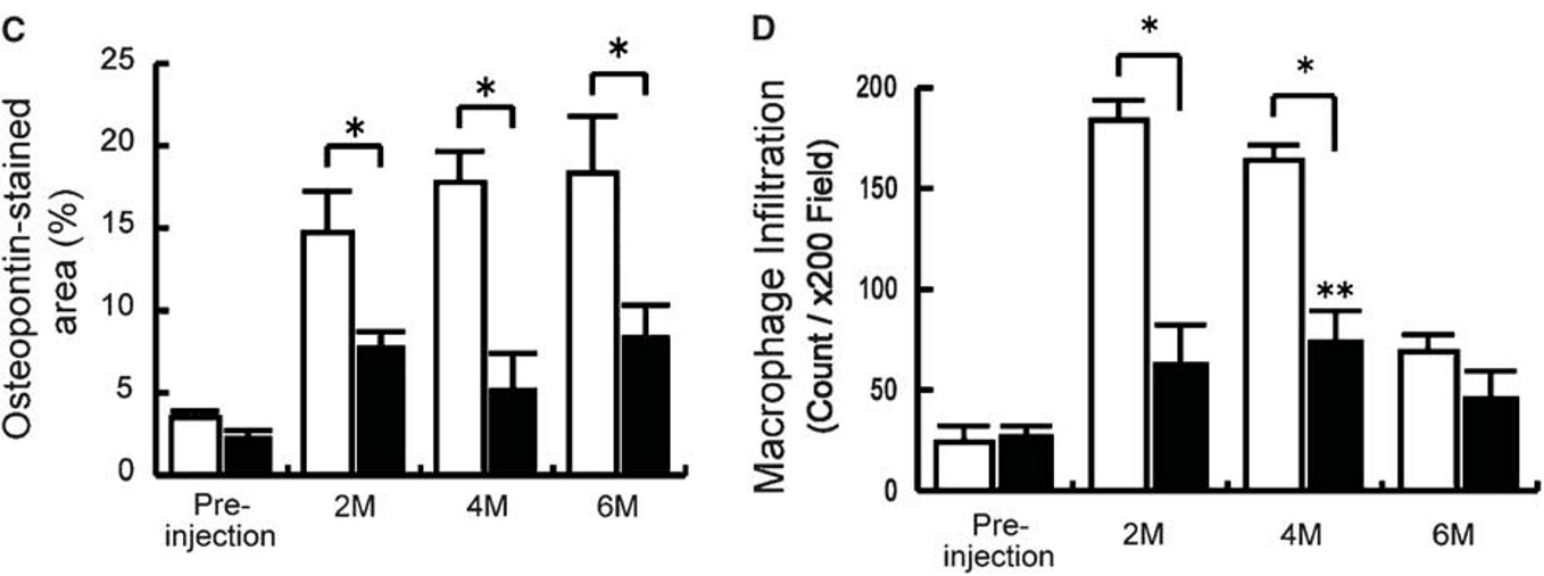

Figure 3 Type I collagen and osteopontin expression, and macrophage infiltration in the tubulointerstitium of STZ-induced $M d k^{+/+}$and $M d k^{-/-}$mice. (A) Immunofluorescence staining for type I collagen at 4 months. A glomerulus (G) is located at the center of each photo. (a) Mdk ${ }^{+/+}$mouse; (b) Mdk ${ }^{-/-}$ mouse. Bar, $50 \mu \mathrm{m}$. (B) Immunohistochemical staining of the tubulointerstitium with osteopontin antibody at 6 months. (a) $M d k^{+/+}$mouse; (b) $M d k^{-/-}$ mouse. Bar, $50 \mu \mathrm{m}$. (C) Morphometric analysis of the osteopontin staining in $M d k^{+/+}$and $M d k^{-1-}$ mice. Bar, $50 \mu \mathrm{m}$. $n=8$. (D) The numbers of macrophages that had infiltrated into the tubulointerstitium pre-injection, and at 2, 4, and 6 months were determined under $\times 200$ magnification. Data are means \pm s.e. White columns, Mdk $+/+$ mice; black columns, Mdk-/- mice. ${ }^{\star} P<0.01 ;{ }^{*} P<0.05$ vs $M d k^{+/+}$at pre-injection, $n=12$.

suggesting that the in vivo $\mathrm{MK}$ induction is not due to a direct effect of STZ.

$\mathrm{MK}$ is also expressed in macrophages. ${ }^{22}$ Therefore, MK from macrophages might contribute to the pathogenesis of diabetic nephropathy. Indeed, MK expression in macrophages was enhanced by $\mathrm{H}_{2} \mathrm{O}_{2}$ and high glucose in a dose- or time-dependent manner (Figure 5e-h). Thirty hours of exposure to high glucose was chosen because MK induction was always observed between 24 and $48 \mathrm{~h}$, and an exposure longer than $48 \mathrm{~h}$ induced cell death (data not shown).

We then determined MCP-1 expression in primary TEC by ELISA. High glucose induced MCP-1 expression significantly 
A

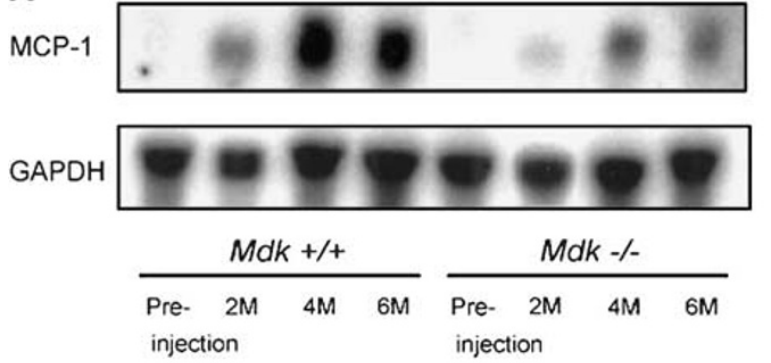

B

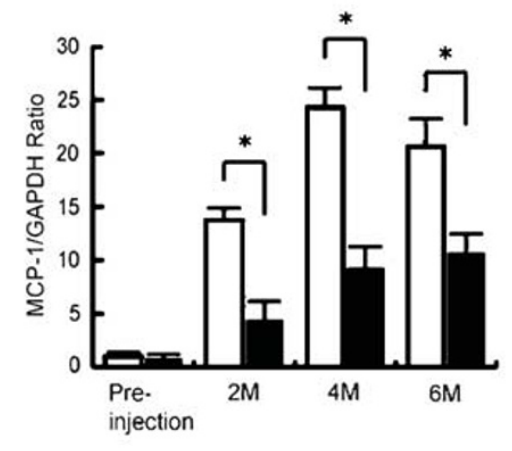

C

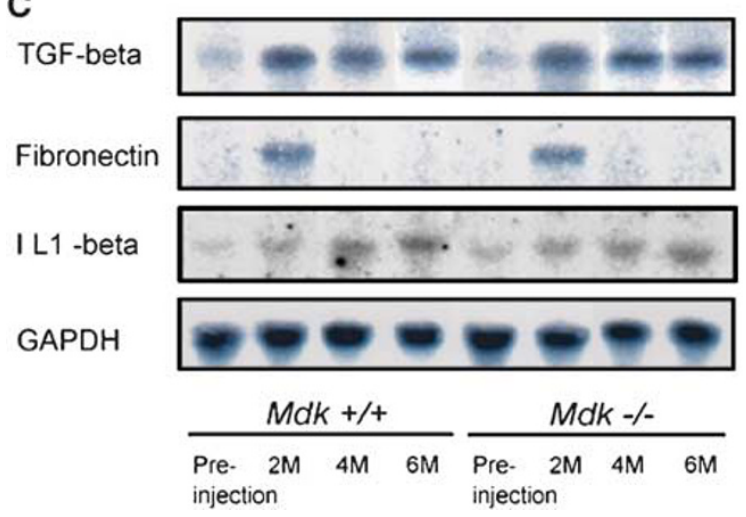

D

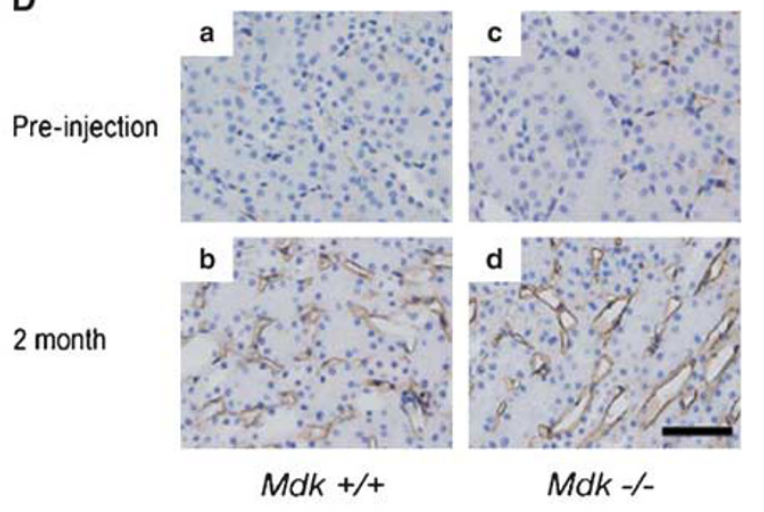

E

ICAM-1

beta-Actin
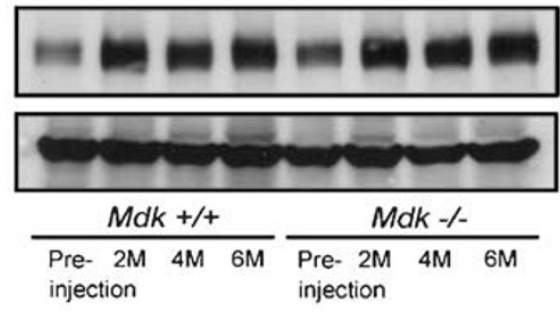

$\mathbf{F}$

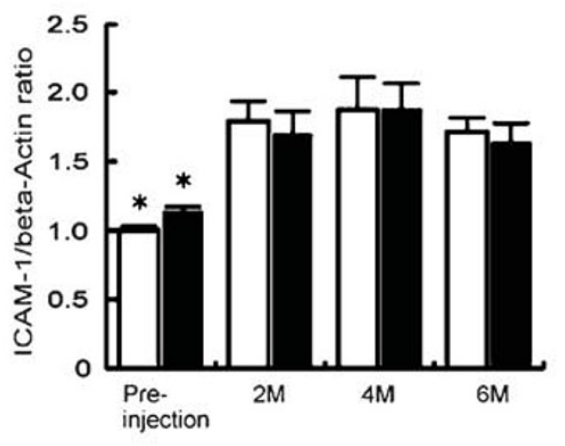

Figure 4 Chemokine and ICAM-1 expression in kidneys of STZ-treated $M d k^{+/+}$and $M d k^{-/-}$mice. (A) Time course of MCP-1 mRNA expression. MCP-1 mRNA was measured pre-injection, and at 2, 4, and 6 months, by Northern blotting. (B) The intensity of MCP-1 bands in (A) was normalized as to GAPDH mRNA. Data are means \pm s.e. ${ }^{*} P<0.05$. $n=12$. (C) TGF- $\beta_{1}$, fibronectin and IL1- $\beta$ mRNA expression pre-injection, and at 2, 4, and 6 months, on Northern blotting. (D) Immunohistochemical staining of the tubulointerstitium with ICAM-1 antibody. (a-b) Mdk ${ }^{+/+}$mice; (c-d) Mdk ${ }^{-/-}$mice. Bar, $50 \mu \mathrm{m}$. (E) Time course of ICAM-1 protein expression. ICAM-1 protein was determined by Western blotting. ICAM-1 was measured pre-injection, and at 2, 4, and 6 months. (F) The intensity of ICAM- 1 bands in (E) was normalized as to that of $\beta$-actin. Data are means \pm s.e. White columns, Mdk $+/+$ mice; black columns, Mdk- $/-$ mice. ${ }^{*} P<0.05$ vs 2,4 and 6 M. $n=6$.

more in $M d k^{+/+}$TEC than in $M d k^{-/-}$ones (Figure 6a). To determine whether the difference in MCP-1 expression between $M d k^{+1+}$ and $M d k^{-1-}$ mice is due to the presence or absence of MK, we examined the effect of the MK protein on $M d k^{-/-}$cells. In $\mathrm{Mdk}^{-/-}$cells exposed to $20 \mathrm{mM}$ D-glucose in the presence of $100 \mathrm{ng} / \mathrm{ml} \mathrm{MK}$, MCP-1 expression was induced in a profile similar to that in the case of $M d k^{+/+}$cells exposed to $20 \mathrm{mM}$ D-glucose (Figure $6 \mathrm{~b}$ ).

\section{DISCUSSION}

Inflammatory cell recruitment to inflammatory sites is regulated through a well-known cascade-like mechanism. ${ }^{23-26}$ Thus, selectins on inflammatory cells or endothelial cells bind to their ligands, and then induce the tethering and rolling of inflammatory cells on endothelial cells. Chemokines such as MCP-1 on the endothelium are recognized by their receptors on inflammatory cells, ${ }^{25}$ and then activate integrins. Integrins further recognize their ligands on the endothelium. For example, $\alpha_{1} \beta_{2}$-integrin recognizes ICAM-1. The firm adhesion of inflammatory cells to the endothelium is now well established, and inflammatory cells transmigrate across the endothelium into interstitial tissues. The concept that inflammation plays a crucial role in the pathogenesis of diabetic nephropathy has been recently emerging, although the principal pathology of diabetic nephropathy comprises glomerular sclerosis and associated changes in nephrons. Firstly, 
a

Midkine

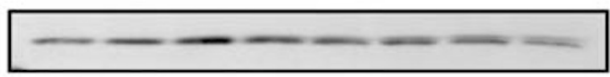

beta-Actin

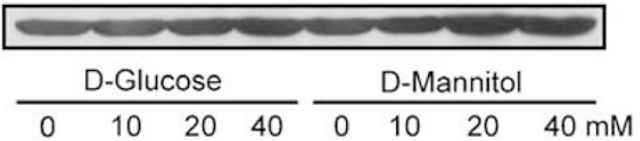

b

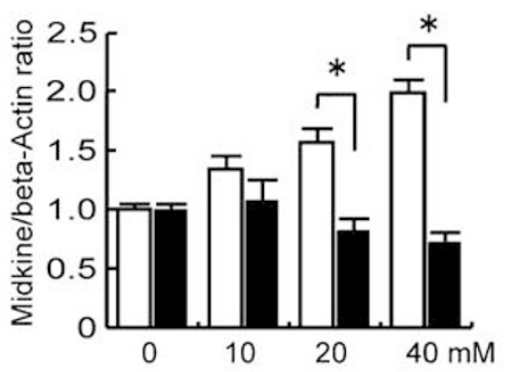

C

Midkine

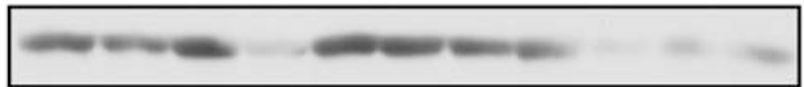

beta-Actin
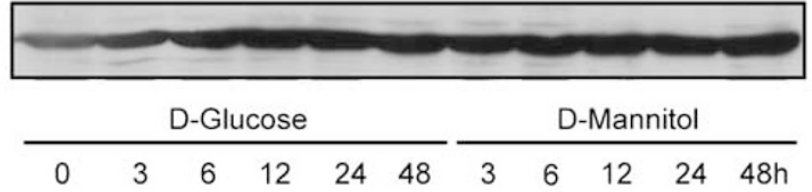

d

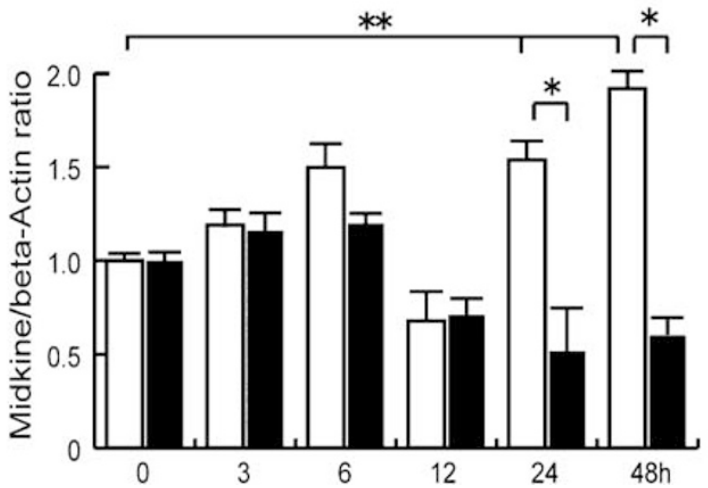

e

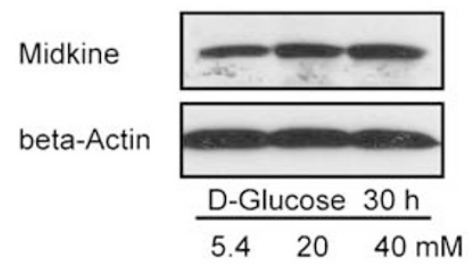

f

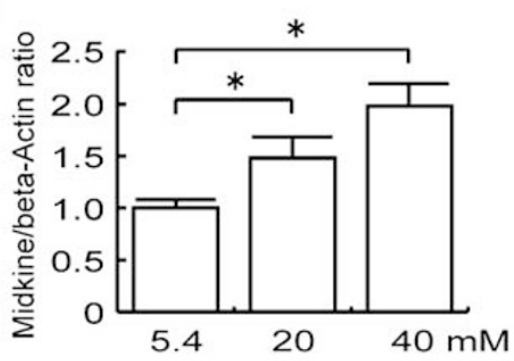

g

Midkine

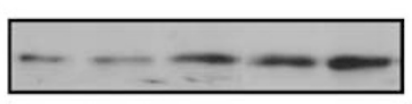

beta-Actin

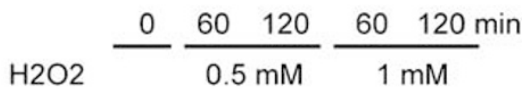

h

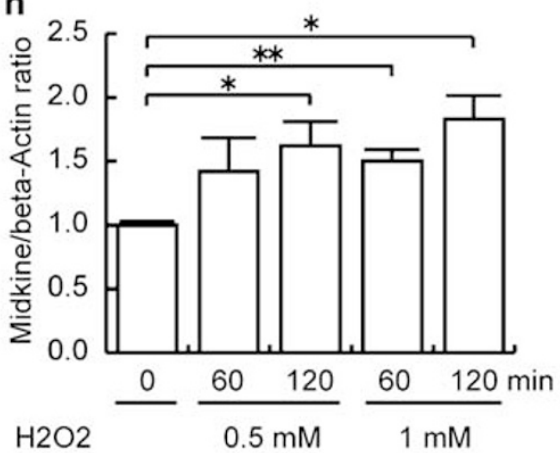

Figure $5 \mathrm{MK}$ protein expression in $\mathrm{Mdk}^{+/+}$tubular epithelial cells and peritoneal-elicited macrophages on exposure to high glucose or hydrogen peroxide. (a) Primary cultured $M d k^{+/+}$TEC were treated with different concentrations of D-glucose or D-mannitol $(0,10,20$ or $40 \mathrm{mM})$ for $24 \mathrm{~h}$. MK protein levels were determined by Western blotting. (b) The intensity of MK bands in (a) was normalized as to that of $\beta$-actin. Data are means \pm s.e. for three independent experiments. White columns, D-glucose; black columns, D-mannitol. ${ }^{*} P<0.05$. (c) Time course of MK expression in TEC on exposure to $20 \mathrm{mM}$ D-glucose or D-mannitol. MK protein levels were determined by Western blotting. (d) Normalized intensity of MK bands in (c). Data are means \pm s.e. for three independent experiments. White columns, D-glucose; black columns, D-mannitol. ${ }^{\star} \mathrm{P}<0.01 ;{ }^{*} \mathrm{P}<0.05 \mathrm{vs} \mathrm{Mdk^{+/+ }} \mathrm{TEC}$ at $0 \mathrm{~h}$. (e) $M d k^{+/+}$peritoneal-elicited macrophages (PEMs) were treated with different concentrations of D-glucose $(5.4,20$ or $40 \mathrm{mM})$ for $30 \mathrm{~h}$. MK protein levels were determined by Western blotting. (f) Normalized intensity of $\mathrm{MK}$ bands in (e). Data are means \pm s.e. for three independent experiments. ${ }^{\star} P<0.05$. (g) PEMs were incubated with 0.5 or $1 \mathrm{mM}$ $\mathrm{H}_{2} \mathrm{O}_{2}$ for 60 or $120 \mathrm{~min}$, respectively. MK protein levels were determined by Western blotting. (h) Normalized intensity of MK bands in (g). Data are means \pm s.e. for three independent experiments. ${ }^{*} P<0.05 ;{ }^{*} P<0.01$.

studies involving human biopsy specimens and animal models have revealed that macrophage infiltration is a characteristic of diabetic nephropathy. ${ }^{26-30}$ Secondly, mice deficient in MCP-1 or ICAM-1 exhibit a marked reduction of nephropathy in the type I diabetes model with STZ., ${ }^{4,6}$ MCP-1 or ICAM-1 deficiency also prevent nephropathy in type II diabetic $\mathrm{db} / \mathrm{db}$ mice. ${ }^{5,7}$ We found another key molecule for the inflammation in diabetic nephropathy in the current study.
We demonstrated in this study that there were marked differences between $M d k^{+1+}$ and $M d k^{-1-}$ mice in terms of tubular damage, macrophage infiltration and MCP-1 expression in diabetic nephropathy induced by STZ, the levels being much lower in $M d k^{-1-}$ mice. Complementary to this, MK expression was upregulated by high glucose in primarycultured TEC. Primary-cultured TEC from $\mathrm{Mdk}^{+/+}$mice produced significantly more MCP-1 in response to high 

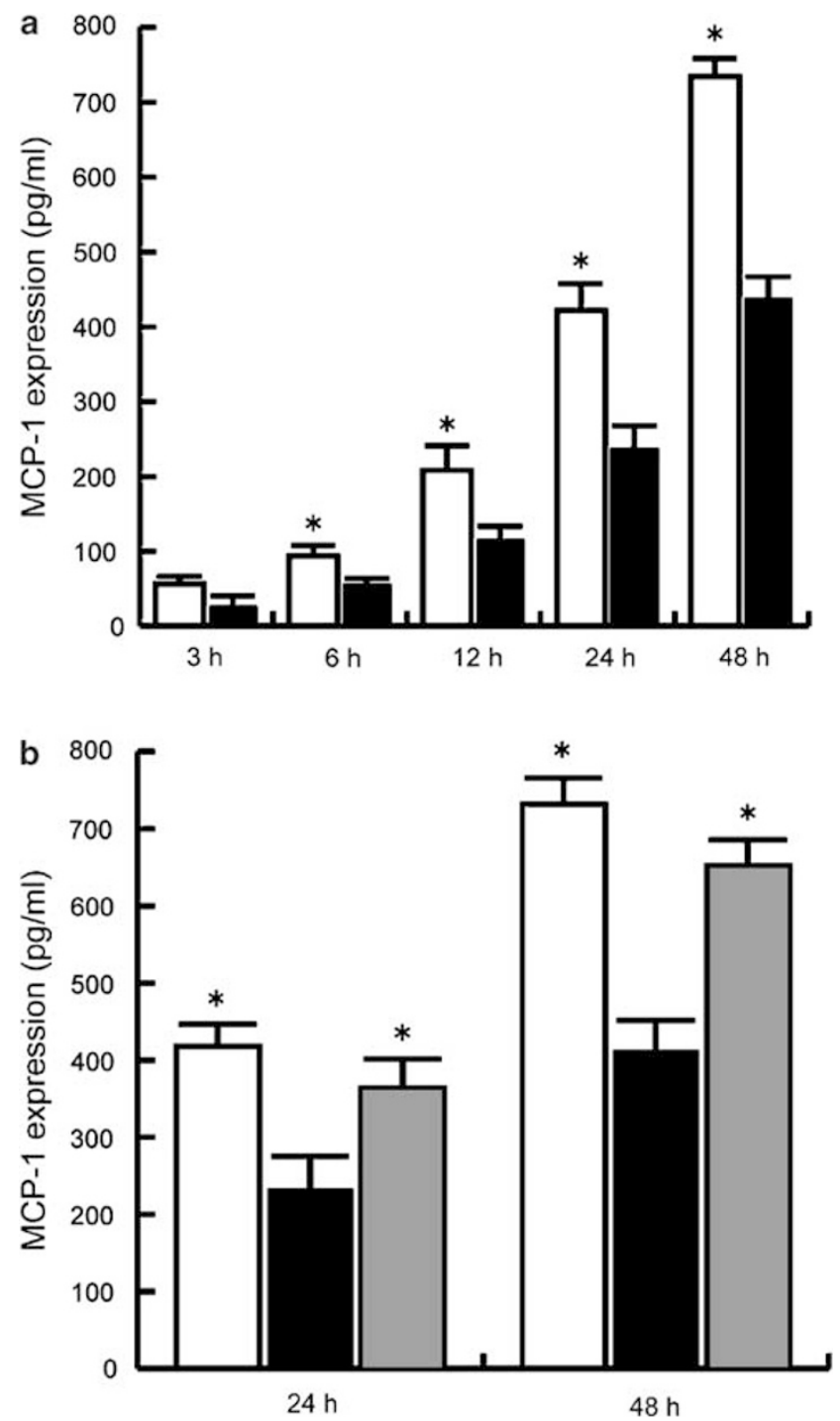

Figure $6 \mathrm{MCP}-1$ expression in $\mathrm{Mdk}^{+/+}$or $\mathrm{Mdk}^{-/-}$TECs under high glucose conditions. (a) MCP-1 protein expression was measured by ELISA. Data are means \pm s.e. for four independent experiments. White columns, $\mathrm{Mdk}^{+/+}$; black columns, $\mathrm{Mdk}^{-1-}$. ${ }^{*} P<0.05$ vs $\mathrm{Mdk}^{-1-}$ TEC at each time point. (b) MCP-1 protein expression in $M d k^{-/-}$TEC exposed to $100 \mathrm{ng} / \mathrm{ml} \mathrm{MK}$ was equal to that in $\mathrm{Mdk}^{+/+}$under high glucose conditions. Data are means \pm s.e. for three independent experiments. White columns, $\mathrm{Mdk}^{+/+}$; black columns, $\mathrm{Mdk}^{-/-}$; gray columns, $\mathrm{Mdk}^{-/-}$with $100 \mathrm{ng} / \mathrm{ml} \mathrm{MK}$ added. ${ }^{*} P<0.05$ vs $\mathrm{Mdk}^{-1-}$ TEC at each time point.

glucose than those from $\mathrm{Mdk}^{-/-}$mice. Exogenous MK along with high glucose induced MCP-1 expression in $M d k^{-1-}$ TEC at a comparable level to that in $M d k^{+/+}$TEC. These results indicate that MK plays a critical role in the pathogenesis of the tubulointerstitial damage associated with diabetic nephropathy. However, the diminished level of injury and scarring in $M d k^{-/-}$mice might not necessarily be the result of the absence of MK from the tubulointerstitium. We do not exclude the possibility that these phenomena are secondary to the reduced glomerular injury and the lower level of proteinurea found in $M d k^{-/-}$mice. ${ }^{10}$

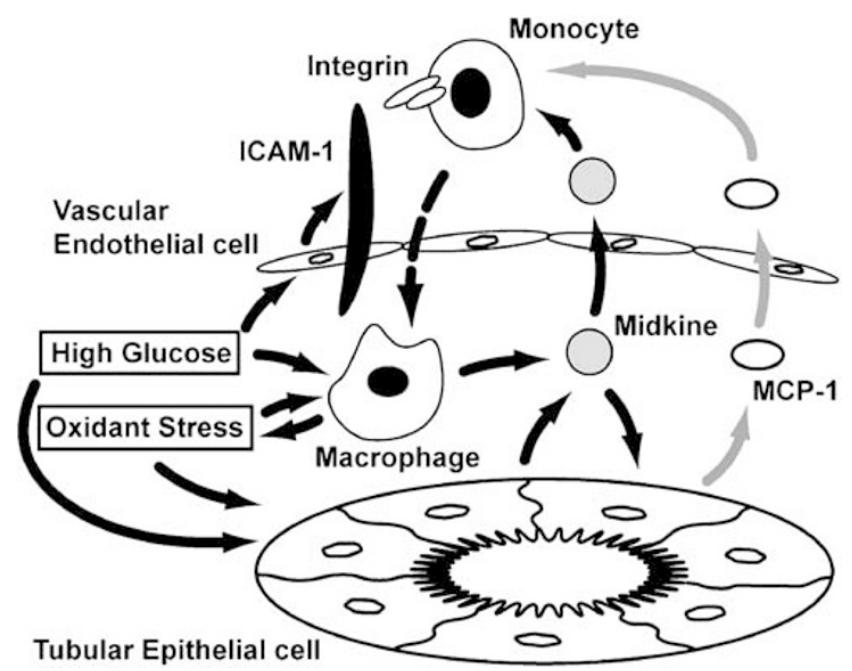

Figure 7 Schematic diagram showing the possible relationship between MK and macrophage infiltration, which promotes interstitional renal damage.

Considering that a deficiency of MCP- 1 or ICAM- 1 causes a reduction of diabetic nephropathy, ${ }^{4-7}$ it is noteworthy that only MCP-1 expression, that is, not that of ICAM-1, was affected in $\mathrm{Mdk}^{-/-}$mice. Therefore, the effect of MK deficiency may be attributable to the suppression of MCP-1 expression. MCP-1 suppression will consequently cause suppression of macrophage infiltration. In this regard, MK itself should be paid attention in addition to MCP-1, because MK directly exhibits chemotactic activity toward macrophages. ${ }^{15}$ In addition, reduction of osteopontin expression in $M d k^{-/-}$mice is also important, because not only MCP-1 but also osteopontin is known to promote macrophage accumulation. ${ }^{31}$

Our study revealed the source of MK expression, namely TEC and macrophages. MCP-1 expression is also induced in these cells, as shown in this study as well as in previous reports including one reporting MCP-1 induction in TEC in vivo in STZ-induced diabetes models. ${ }^{6,10}$ These data collectively suggest that there is a molecular and cellular circuit, as shown in Figure 7. Thus, MK, whose production is upregulated by high glucose in TEC and macrophages, directly induces monocyte recruitment and also indirectly through activation of MCP-1. Moreover, our previous study ${ }^{16}$ and the current one demonstrated that oxidant stress enhances MK expression in TEC and macrophages, respectively. Therefore, it is conceivable that once macrophages have infiltrated, reactive oxygen species produced by them will further activate the molecular and cellular circuit (Figure 7).

With regard to intracellular signaling molecules, p38 mitogen-activated kinase and NF- $\kappa \mathrm{B}$ have been implicated in tubulointerstitial inflammation associated with diabetic nephropathy. Phosphorylated p38-positive cells in patients with diabetic nephropathy reflects the severity of tubulointerstitial lesions. ${ }^{32}$ Phosphorylated p38 is also detected in interstitial cells of mouse models. ${ }^{33} \mathrm{NF}-\kappa \mathrm{B}$ was identified 
through unbiased mRNA expression screening of tubulointerstitial compartments of human renal biopsy of diabetic nephropathy patients and normal controls. ${ }^{8}$ Therefore, the relationship between $\mathrm{MK}$ and these molecules is worthy of investigation.

The phenomena revealed in this study raised some pertinent questions. First, TGF- $\beta$ expression was induced to a similar extent at 2 months and afterwards in $\mathrm{Mdk}^{+/+}$and $M d k^{-/-}$mice (Figure 4C). Nevertheless, fibrosis was severer in $M d k^{+1+}$ mice (Figure 2C). Are other molecules rather than TGF- $\beta$ involved in fibrosis in this model? A direct link between MK and TGF- $\beta$ cannot be drawn from the present data. Second, MCP-1 and osteopontin expressions were significantly more increased in $M d k^{+1+}$ mice than in $M d k^{-1}$ mice until 6 months after STZ injection (Figure 3C and 4B). However, macrophage infiltration was low and at a similar level at 6 months although there was a big difference between the two genotypes in earlier period (Figure 3D). Could a suppressive mechanism such as induction of inhibitory molecule(s) and/or a physical barrier occur at 6 months? These issues remain to be investigated.

In summary, we have identified MK as a key molecule not only in mesangial-mediated nephropathy, as described previously, ${ }^{10}$ but also as a direct activator of the tubulointerstitial inflammatory process associated with diabetic nephropathy. This finding opens up new avenues that may facilitate research on the cause of and the development of therapeutics for human diabetic nephropathy.

\section{ACKNOWLEDGEMENTS}

We thank N Asano, T Katahara and Y Sawa for the excellent technical assistance, and H Aoki for the secretarial assistance. Supported by Grants-inAid from the Ministry of Education, Science, Sports and Culture of Japan (14580647 to KK; 15590849 to YY).

1. Bojestig $M$, Arnqvist $H J$, Hermansson $G$, et al. Declining incidence of nephropathy in insulin-dependent diabetes mellitus. N Engl J Med 1994;330:15-18.

2. Krolewski M, Eggers PW, Warram JH. Magnitude of end-stage renal disease in IDDM: a 35 year follow-up study. Kidney Int 1996;50: 2041-2046.

3. Wada T, Furuichi K, Sakai N, et al. Up-regulation of monocyte chemoattractant protein-1 in tubulointerstitial lesions of human diabetic nephropathy. Kidney Int 2000;58:1492-1499.

4. Okada S, Shikata K, Matsuda M, et al. Intercellular adhesion molecule1-deficient mice are resistant against renal injury after induction of diabetes. Diabetes 2003;52:2586-2593.

5. Chow FY, Nikolic-Paterson DJ, Ozols E, et al. Intercellular adhesion molecule-1 deficiency is protective against nephropathy in type 2 diabetic db/db mice. J Am Soc Nephrol 2005;16:1711-1722.

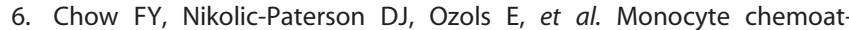
tractant protein-1 promotes the development of diabetic renal injury in streptozotocin-treated mice. Kidney Int 2006;69:73-80.

7. Chow FY, Nikolic-Paterson DJ, Ma FY, et al. Monocyte chemoattractant protein-1-induced tissue inflammation is critical for the development of renal injury but not type 2 diabetes in obese $\mathrm{db} / \mathrm{db}$ mice. Diabetologia 2007;50:471-480.

8. Schmid H, Boucherot $A$, Yasuda $Y$, et al. Modular activation of nuclear factor-kappaB transcriptional programs in human diabetic nephropathy. Diabetes 2006;55:2993-3003.
9. Navarro JF, Mora-Fernandez C. The role of TNF-alpha in diabetic nephropathy: pathogenic and therapeutic implications. Cytokine Growth Factor Rev 2006;17:441-450.

10. Kosugi T, Yuzawa Y, Sato W, et al. Growth factor midkine is involved in the pathogenesis of diabetic nephropathy. Am J Pathol 2006;168:9-19.

11. Kadomatsu K, Muramatsu T. Midkine and pleiotrophin in neural development and cancer. Cancer Lett 2004;204:127-143.

12. Ikematsu S, Nakagawara A, Nakamura Y, et al. Correlation of elevated level of blood midkine with poor prognostic factors of human neuroblastomas. Br J Cancer 2003;88:1522-1526.

13. Takei $Y$, Kadomatsu K, Matsuo $S$, et al. Antisense oligodeoxynucleotide targeted to midkine, a heparin-binding growth factor, suppresses tumorigenicity of mouse rectal carcinoma cells. Cancer Res 2001;61:8486-8491.

14. Maruyama $\mathrm{K}$, Muramatsu $\mathrm{H}$, Ishiguro N, et al. Midkine, a heparinbinding growth factor, is fundamentally involved in the pathogenesis of rheumatoid arthritis. Arthritis Rheum 2004;50:1420-1429.

15. Horiba M, Kadomatsu K, Nakamura E, et al. Neointima formation in a restenosis model is suppressed in midkine-deficient mice. J Clin Invest 2000;105:489-495.

16. Sato $W$, Kadomatsu K, Yuzawa $Y$, et al. Midkine is involved in neutrophil infiltration into the tubulointerstitium in ischemic renal injury. J Immunol 2001;167:3463-3469.

17. Kawai $H$, Sato $W$, Yuzawa $Y$, et al. Lack of the growth factor midkine enhances survival against cisplatin-induced renal damage. Am J Pathol 2004; 165:1603-1612.

18. Hayashi K, Banno H, Kadomatsu K, et al. Antisense oligodeoxyribonucleotide as to the growth factor midkine suppresses neointima formation induced by balloon injury. Am J Physiol Heart Circ Physiol 2005;288:2203-2209.

19. Sato W, Takei Y, Yuzawa Y, et al. Midkine antisense oligodeoxyribonucleotide inhibits renal damage induced by ischemic reperfusion. Kidney Int 2005;67:1330-1339.

20. Nahori MA, Fournie-Amazouz E, Que-Gewirth NS, et al. Differential TLR recognition of leptospiral lipid $A$ and lipopolysaccharide in murine and human cells. J Immunol 2005;175:6022-6031.

21. Nangaku M, Pippin J, Couser WG. C6 mediates chronic progression of tubulointerstitial damage in rats with remnant kidneys. J Am Soc Nephrol 2002;13:928-936.

22. Inoh K, Muramatsu H, Ochiai K, et al. Midkine, a heparin-binding cytokine, plays key roles in intraperitoneal adhesions. Biochem Biophys Res Commun 2004;317:108-113.

23. Butcher EC. Leukocyte-endothelial cell recognition: three (or more) steps to specificity and diversity. Cell 1991;67:1033-1036.

24. Constantin G, Majeed M, Giagulli C, et al. Chemokines trigger immediate $\beta 2$ integrin affinity and mobility changes: differential regulation and roles in lymphocyte arrest under flow. Immunity 2000;13:759-769.

25. Segerer $\mathrm{S}$, Alpers CE. Chemokines and chemokine receptors in renal pathology. Curr Opin Nephrol Hypertens 2003;12:243-249.

26. Kluth DC, Erwig LP, Rees AJ. Multiple facets of macrophages in renal injury. Kidney Int 2004;66:542-557.

27. Bohle A, Wehrmann M, Bogenschutz $O$, et al. The pathogenesis of chronic renal failure in diabetic nephropathy. Investigation of 488 cases of diabetic glomerulosclerosis. Pathol Res Pract 1991;187: 251-259.

28. Furuta $T$, Saito $T$, Ootaka $T$, et al. The role of macrophages in diabetic glomerulosclerosis. Am J Kidney Dis 1993;21:480-485.

29. Sassy-Prigent C, Heudes D, Mandet C, et al. Early glomerular macrophage recruitment in streptozotocin-induced diabetic rats. Diabetes 2000:49:466-475.

30. Chow F, Ozols E, Nikolic-Paterson DJ, et al. Macrophages in mouse type 2 diabetic nephropathy: correlation with diabetic state and progressive renal injury. Kidney Int 2004;65:116-128.

31. Xie $Y$, Sakatsume $M$, Nishi $S$, et al. Expression, roles, receptors, and regulation of osteopontin in the kidney. Kidney Int 2001;60:1645-1657.

32. Sakai N, Wada T, Furuichi $\mathrm{K}$, et al. Involvement of extracellular signalregulated kinase and p38 in human diabetic nephropathy. Am J Kidney Dis 2005;45:54-65.

33. Adhikary L, Chow F, Nikolic-Paterson DJ, et al. Abnormal p38 mitogenactivated protein kinase signalling in human and experimental diabetic nephropathy. Diabetologia 2004;47:1210-1222. 